Session 2793

\title{
Research to Commercialization: Entre/Intrapreneurship of High Technology University Research for Creation of Local Start-up Companies
}

\author{
Ken Vickers, John Todd \\ University of Arkansas
}

\begin{abstract}
A three-course technology commercialization sequence has been initiated at the University of Arkansas under the financial support of the National Collegiate Inventors and Innovators Alliance (http://www.nciia.org). These courses combine Masters students from business, science, engineering, and law schools into teams in the classroom. The objective of the first class in the sequence (during the spring semester) is to introduce the elements of the evaluation process that is used to decide if a research area is a suitable candidate for commercialization (in either an entrepreneurial or intrapreneurial environment). The students then apply this evaluation process to current on-campus research results, select a suitable commercialization candidate, and work with the technology transfer office and research professor to commercialize the research during the following summer and fall semesters.
\end{abstract}

The first course in the sequence was initiated in the Spring 2000 semester with mixed results. This paper will introduce the detailed class plan and course materials, an analysis of class concept performance after its first year of operation, and a discussion of changes incorporated into the class for the spring 2001 semester. The reader may examine the on-line course materials at the web site http://cavern.uark.edu:8900/ by entering as a guest user and then selecting course MGMT 5383.

\section{Introduction}

Widely divergent engineering and science societies across the country have convened working groups from industry, government, and academe to examine the education received by technology degree students in our colleges and universities. These groups were convened not because the US educational system was broken, but rather to identify characteristics that would move it to the next performance level for the good of our students, businesses, and communities.

Examination of the sections of the reports of these groups dealing with technology businesses showed many items that were common across many of the studies:

- The need for interdisciplinary studies (www.nsf.gov/igert)

- The need for business training of technologists

Proceedings of the 2001 American Society for Engineering Education Annual Conference \& Exposition Copyright (O) 2001, American Society for Engineering Education 
- The negative impact of bad business decisions by technologists

- The need for communication training between business students and technologists

- The need to respond to rapid changes in technology based businesses

- The lack of team based performance metrics in college

- The lack of technology and business school educational partnerships

Students in engineering and science programs are typically not introduced to entrepreneurial approaches to commercialization of advanced research within their graduate curricula. Of the courses that do exist, they are either taught within the science/technology department or they are taught as a service course by the appropriate business department on that campus. These courses are monolithic in their class composition, being normally populated only by students within the science/technology department or college.

In a similar fashion, the courses taught within the business departments on entrepreneurial technology startups and management of intrapreneurial activities in technology companies are also monolithic in their student population. The students in these classes study applications of general business theory to high technology fields with no knowledge of how technology is created or evolves.

What both approaches lack is the exposure of the students from one background (technology or business) with students from the other background. This prevents both types of students from understanding the tremendous gap in approach and analysis of technology business opportunities that exist between the two educational perspectives. It is this lack of understanding that can lead to the failure of a technology product opportunity through incomplete understanding the startup team of either the market or technology space in which the new venture must reside.

An approach to resolve this problem is in its second year at the University of Arkansas. An entrylevel graduate course sequence in "commercialization of research" has been created by the team of Dr. John Todd (Management Department in the Walton College of Business Administration) and Professor Ken Vickers (Physics Department in the Fulbright College of Arts and Sciences). In this course sequence, graduate students from business, science, engineering, and law graduate programs are brought together to examine through interdisciplinary student team investigations the process by which research successfully migrates to full commercialization.

This course sequence has four objectives. First, the course sequence is designed to demonstrate to both groups of students the necessity of having both types of educational expertise in any technology product development venture. Second, the course sequence is designed to increase the confidence level of all the students that they can successfully create a new technology venture. Third, the course sequence is designed to bring a potential educated venture creation student team into partnership with a faculty member with research on the cusp of commercialization. Fourth, the course sequence provides hands-on skills for technology commercialization and related management responsibilities. These objectives together are expected to result in an invigorated 
entrepreneurial culture on this campus and the creation of new technology venture firms in the state of Arkansas, as well as enhancing the value of the students for future intrapreneuring technological employers.

In this paper this course sequence and the results of the first year of teaching the course will be described. Changes that are planned for the Spring 2001 semester will also be discussed.

\section{Course sequence knowledge content}

In order to achieve the course objectives, strategies were defined to give the students the knowledge and tools necessary for both their future career success and for immediate new venture creation in the state. These strategies were:

1. To increase understanding of the creation and evolution of high-tech entrepreneur ventures.

2. To identify the basic decisions that an entrepreneur faces, including technology selection, product design, market analysis, financing, and general management of operations.

3. To develop leadership skills for identification and exploitation of technological opportunities, risk assessment, finding resources, and managing growth.

4. To identify University of Arkansas mature research efforts and commercialize them in partnership with the Technology Transfer Office and the originating professor.

These strategies were to be implemented in a twelve-month sequence of three courses, with the twelve months spanning a normal January to December calendar year. The three courses are summarized as follows.

Name: $\quad$ MGMT 5383 Intra/Entrepreneurship of Technology to Market

Level: $\quad 3$ semester-hours, spring semester

Purpose: Overview of research commercialization process; evaluate target research

Name: $\quad$ MGMT 548V Technology Intra/Entrepreneurship Planning

Level: $\quad 1$ semester-hour, summer 12-week semester

Purpose: $\quad$ Detailed planning of commercialization sequence of selected research

Name: $\quad$ MGMT 5383L Technology Intra/Entrepreneurship Implementation

Level: $\quad 3$ semester-hour, fall semester

Purpose: $\quad$ Prototype production or licensing of commercialized research

The course sequence is initiated in the spring semester with MGMT 5383. The student population of the course is a combination of (1) technology students from traditional graduate programs that have an inclination toward entrepreneurial activity, (2) students from business graduate programs that have a specific interest in high technology business operation, and (3) students from the 
interdisciplinary technology graduate program in Microelectronics-Photonics (http://www.uark.edu/depts/microep). The first two groups of students are self-selected for the course because of their individual interests, while the third group's students are required to take the course as a core course of the microEP core curriculum.

Students in the class are formed into small teams, with each team containing at least one student from science/engineering and one from business. The class is taught using a seminar methodology, meeting twice per week in eighty-minute periods, and is team-taught to bring expertise from both the business and technology side into each class meeting. A detailed calendar is published at the start of the semester listing the subject matter that will be covered in each class, and any material not covered during the class is considered the responsibility of the students to master independently.

The course content follows in general the organization of the book Technological Entrepreneurism by Mario W. Carullo, P.E., but is heavily supplemented by analysis of Harvard Business School case studies. Subjects are organized into multiple-day blocks in which one or two book chapters are first discussed by the professors and then the material covered is related to a case study by a student team. Another student team follows, applying the concepts learned to the specific research area chosen at the beginning of the semester.

In this fashion the students are led through a clear sequence of events that provides them with a roadmap for an independent evaluation of their future research's prospects for commercialization. The students participate in detailed and vigorous discussions on such topics as competitive market and technology space analysis, total cost of manufacturing, marketing approaches, business plans, resource allocation, TQM, intellectual property protection, etc.

This results in the students not only being introduced to the critical steps of the analysis process, but also in the students creating an ongoing reference library of relevant current business decisions from their presentations. In addition, these team presentations provide an opportunity for peer feedback on the clarity and appropriateness of many different presentation methods attempted by the student teams.

It is during the vigorous classroom discussions that the students find they must suddenly learn to communicate in an entirely different fashion than they have successfully used in their academic careers to this point. Technology students find that a leading-edge technology product is seen by their business student colleagues as nothing other than a generic mechanism for market manipulation. At the same time, the business students find their formulistic view of a new technology product development cannot be reconciled with the complicated technology and manufacturing space that their technology student colleagues navigate with complete confidence. Together, they form a new common understanding of the knowledge and skills needed to drive successful venture company in this technology driven economy. 
At the end of the spring semester, the students use their newfound common understanding to participate in a detailed discussion of their analysis of the targeted research with the faculty member who is the originator of the research. This analysis will be similar to an analysis and discussion that would occur if the faculty member was approaching a venture capital firm for early developmental funding. This allows the students to participate in the discussion in both the role of the venture capitalist and the role of the owner of a technology startup venture.

At the conclusion of the spring semester course, the first two objectives of the course sequence have been met through extensive practice of the first three strategies. It is then time to drive forward to the third objective, the creation of new venture firms in the state of Arkansas.

The immediate success of this third objective is largely dependent on the proper identification of a target research area by the University of Arkansas' Office of Technology Transfer. The research brought to the class for analysis during the spring semester should have some level of intellectual protection already in place to minimize the need for non-disclosure documentation, but should not have any firm commercialization plans in place. The best possible outcome of the spring course is for a sub-group of the class population to have (1) become passionately convinced of the commercialization prospects of the research and (2) formed a strong working relationship with the research's originating faculty member.

At this time the sub-group of students would register for the one semester-hour summer seminar series for commercialization planning of the research (MGMT 548V Technology Intra/Entrepreneurship Planning). In this seminar class format, the students would be mentored by the seminar leader as they create a detailed implementation plan with the research professor. Part of this plan would be to identify the method by which the students would be given a small but appropriate equity position in the commercialization venture in return for their becoming the low cost startup team for the professor.

By the start of the fall semester, the students would have a comprehensive commercialization plan in place and would begin implementation of the plan with the research professor under the mentorship and monitoring of the classroom professor in MGMT 5383L Technology Intra/Entrepreneurship Implementation. The classroom activities would be fully focused on the new venture startup activities, with the students now organized into teams to manage the different aspects of the commercialization effort. Each team would act as an "equivalent management team member", reporting as a group to the other teams on their successes and setbacks.

The best possible outcome of this semester's activities would be either (1) the creation of a new manufacturing facility to at least the prototype stage of manufacturing of their technology product or (2) a completed licensing agreement with an established manufacturing entity. If either of these should occur, it would set the stage to be an immediate indication that we have met the fourth objective of the course as the startup company matures. However, we expect that most of the students in the class will utilize this skill set in a more intrapreneurial role within major high tech 
companies. Under these conditions, it is expected that differentiation between technologists with and without this course should be obvious by the fifth year of their professional careers.

\section{Class outcomes}

All of the outcomes of the classes described to this point in this paper are easy to quantify and track. What is difficult to measure is the classes' impact on the students' entrepreneurial and intrapreneurial successes as they progress through their professional careers. Early anecdotal evidence from the first class from the spring of 2000 is mixed.

First, none of the students that took the first course in the sequence decided to pursue the research opportunity investigated by the class. It is the authors' belief that there were two reasons for the fact that the last two courses in the sequence were not pursued. First, the originating research professors were not passionate in their belief that commercialization was a proper next step. They would have been happy to see someone else put their energy into commercializing their ideas, but were not willing to make the entrepreneurial jump themselves in support of their own product.

Second, the total workload turned out to be much heavier on the students than had been anticipated as the syllabus was being created. In addition, the research target was not introduced until mid-semester, which shortened the time for analysis by the students. Both of these items resulted in a less thorough evaluation of the commercialization opportunity than was optimum. Both of these items have been addressed by the authors in preparation to begin the second pass through the course sequence in the Spring 2001 semester.

It should also be noted that none of the Spring 2000 class members that graduated in May/Summer 2000 have reported back to the program any impact from the course's training on their first six months' career tasks. This is not unexpected, as most newly hired technologists are strongly focused on learning their assigned technology area rather than pursuing intrapreneurial activities.

But one positive note has appeared from a Spring 2000 class member that is still in the PhD microEP graduate program at the University of Arkansas. During the break between the academic year 2000-2001 semesters, the student formed a company to begin offering commercial services based on his research activities. This student notified the authors that he was inclined toward forming a business before taking the course, but that the knowledge he gained in the course gave him the confidence to begin the process now rather than at some point in the future.

Students in this course sequence that graduate with a microEP graduate degree are part of a ten year longitudinal study supported by the University of Arkansas NSF Integrative Graduate Education and Research Training (IGERT) grant that began in 1999. As part of this longitudinal study, the microEP alumni and their supervisors will participate in annual surveys of performance. Included in this survey will be questions to the alumni on the usefulness of the knowledge gained in different courses in their graduate curricula. This will provide us with the data necessary to 
evaluate the impact of this course sequence on early career success of the students.

\section{Conclusion}

This paper was written to give the readers one possible method to increase the level of commercialization of research at an educational institution. The lessons-learned from the first teaching of the course sequence have been presented, along with the course modifications that will result from these lessons.

The authors feel that this type of course is one key element to creating an atmosphere of entrepreneurial success at an educational institution, and will continue to report on the progress generated by this course sequence as it matures over the next several years.

\section{KEN VICKERS}

Ken Vickers is a Research Professor in Physics at the University of Arkansas, and has served as Director of the interdisciplinary Microelectronics-Photonics Graduate Program since April 1998. He worked for Texas Instruments from 1977 through March 1998 in integrated circuit fabrication engineering, the last seven years as Engineering Manager of the TI Sherman IC Wafer Fab. Professor Vickers' technical accomplishments before leaving TI included chairmanship of the Sherman Site Technical Council for six years, election to Senior Member Technical Staff, chairmanship of two corporate level worldwide teams, and authorship of twenty-eight issued patents. He received BS and MS degrees in Physics from the University of Arkansas in 1976 and 1978 respectively.

\section{JOHN TODD}

John Todd is a Professor of Management in the Walton College of Business Administration at the University of Arkansas. He is been Chair of the Management Department, Director of the University Small Business Institute, President of the Association of Graduate Business Directors, member of the Fayetteville City Board of Directors, and Mayor of the City of Fayetteville. He received his BSBA from the University of Arkansas in 1961, his MBA from the University of Texas in 1965, and his DBA from Harvard in 1972. 